\title{
Extreme hypercholesterolaemia and hypertriglyceridaemia in a man newly diagnosed with type 2 diabetes mellitus
}

\section{Ashraf Saleh}

\section{CASE}

A Caucasian man aged 46 years, working as an oil rig area coordinator in remote South Australia, presented with incidental hyperglycaemia. He was sent to an onsite nurse because of lethargy and anorexia over the previous few weeks. The nurse noted an elevated blood sugar level on capillary blood sampling (reading 'high' on the glucometer) and sent him to the nearest regional centre for further investigations. He had not undertaken a medical examination in $>10$ years.

He noticed increasing shortness of breath on exertion, and polydipsia and polyuria progressing over the previous month. He had not had any chest pain, dyspnoea, orthopnoea, palpitations or abdominal symptoms. His family history was unknown, as he had been adopted as a child. He had no previous medical or surgical history and did not take any regular medications. He drank 2-3 standard alcoholic beverages per night on average, occasionally consuming up to six alcoholic beverages in one night.

He was centrally obese, with a blood pressure of 160/98 $\mathrm{mmHg}$ and a resting pulse rate of 104 beats per minute. Jugular venous pressure was undetectable, and he had no peripheral or sacral oedema. He had good peripheral pulses and an intact neurological system. His chest was clear, but there was tenderness in the epigastrium. There was no abdominal mass. His vision was $6 / 5$ bilaterally. Urinalysis showed $3+$ protein and $3+$ glucose but no leukocytes, nitrites or blood. He had an initial non-fasting blood sugar level of $18.9 \mathrm{mmol} / \mathrm{L}$ and was sent for formal blood testing.

\section{QUESTION 1}

What is metabolic syndrome, why is it important, and how prevalent is it in Australia?

\section{QUESTION 2}

How should dyslipidaemia in patients with multiple cardiovascular risk factors be managed, with and without diabetes?

\section{ANSWER 1}

Metabolic syndrome is defined as a concomitant cluster of risk factors including elevated waist circumference (population group-specific), triglycerides $\geq 1.7 \mathrm{mmol} / \mathrm{L}$, high-density lipoproteins (HDL) $<1.0 \mathrm{mmol} / \mathrm{L}$ in men and $<1.3$ $\mathrm{mmol} / \mathrm{L}$ in women, blood pressure $\geq 130 / 85 \mathrm{mmHg}$ and fasting glucose $>5.5 \mathrm{mmol} / \mathrm{L} .{ }^{1}$ The 2006 Bettering the Evaluation and Care of Health study revealed that the prevalence of metabolic syndrome in the Australian population was $15.6 \% .^{2}$ There is a significantly increased risk of macrovascular and microvascular disease seen in people with metabolic syndrome, ${ }^{3}$ with no apparent symptomatology.

\section{ANSWER 2}

A review of available data on cardiovascular comorbidities, including diabetes, suggests a stratified analysis of cardiovascular risk and treatment based on that degree of risk. ${ }^{4}$ Some studies recommend moderate-dose statin therapy for patients with dyslipidaemia aged $\geq 40$ years for primary prevention even without diabetes..$^{5-7}$ More aggressive therapy is considered on a case-by-case basis that incorporates atherosclerotic cardiovascular disease risk factors. The evidence for benefit is strong for patients with diabetes aged $40-75$ years, an age group well represented in statin trials. ${ }^{8,9}$

\section{CASE CONTINUED}

Table 1 displays the patient's initial and five-year follow-up blood test results. The initial blood specimen taken, shown in Figure 1, indicated he had severe dyslipidaemia. He had moderate albuminuria $(259 \mathrm{mg} / \mathrm{L})$ in a first morning sample, with an albumin:creatinine ratio of 35 . His electrolytes, serum proteins and renal, liver and thyroid function tests were all normal. His tests were positive for the apolipoprotein $\mathrm{E}$ gene, which does not predispose him to hypertriglyceridaemia but may be associated with reduced fatty acid oxidation, contributing to the accumulation of tissue and plasma lipids. ${ }^{10}$

He was sent for urgent cardiovascular workup and management of his severe dysglycaemia in a tertiary referral hospital 
by a physician. He had a computed tomography coronary angiogram that identified an occluded right coronary artery and a coronary angiogram showing a chronic complex right coronary artery occlusion, a stenotic small obtuse marginal branch and preserved left ventricular function. A subsequent myocardial perfusion scan showed no inducible ischaemia, suggesting the right coronary artery was well collateralised; therefore, no percutaneous intervention was deemed necessary. He was put on atenolol, aspirin, insulin glargine, insulin aspart, metformin, fenofibrate, rosuvastatin and ramipril.

He had no coronary events for the following five years on this treatment regimen. His biochemical parameters at this time point, comparing them to his initial results, are shown in Table 1. Despite anthropometric measures not significantly improving because of a sedentary lifestyle, his biochemical profile had gained significant headway in establishing a legacy effect to preventing the endpoints of myocardial infarction and stroke.

\section{QUESTION 3}

How should patients with severe dyslipidaemia be managed while awaiting definitive cardiovascular treatment?

\section{QUESTION 4}

How prevalent is dyslipidaemia in patients with type 2 diabetes mellitus (T2DM)?

\section{QUESTION 5}

What is the clinical relevance of the dyslipidaemia in T2DM?

\section{ANSWER 3}

Low-density lipoproteins (LDL) $>4.0$ $\mathrm{mmol} / \mathrm{L}$ or total cholesterol $>7.5 \mathrm{mmol} / \mathrm{L}$ translate to an innately high cardiovascular event risk according to the Guidelines for the management of absolute cardiovascular risk. ${ }^{11}$ This warrants immediate active risk management treatments including simultaneous lipid lowering and blood pressure lowering pharmacotherapy unless contraindicated. The target for blood pressure is $\leq 140 / 90 \mathrm{mmHg}$ unless the patient has diabetes or is exhibiting albuminuria; in this case, $\leq 130 / 80 \mathrm{mmHg}$ is recommended. ${ }^{11}$ Lipids should be brought down with statins as the first-line treatment, to a total cholesterol of $<4.0$ $\mathrm{mmol} / \mathrm{L}$ and LDL of $<2.0 \mathrm{mmol} / \mathrm{L}^{12}$

\section{ANSWER 4}

Dyslipidaemia occurs frequently in T2DM; a recent study in China indicates a prevalence of $67 \%,{ }^{13}$ and in a US study, over $70 \%$ of patients with diabetes did not meet goal lipid levels. ${ }^{14}$

Table 1. Biochemistry profile of the case patient, prior to treatment and five years post-treatment for extreme dyslipidaemia

\begin{tabular}{lrrr}
\hline Parameter & Year 2013 & Year 2018 & Reference range \\
\hline Total cholesterol (mmol/L) & 18.3 & 5.4 & $3.9-5.5$ \\
\hline $\mathrm{HDL}(\mathrm{mmol} / \mathrm{L})$ & $*$ & 0.9 & $0.9-1.5$ \\
\hline $\mathrm{LDL}(\mathrm{mmol} / \mathrm{L})$ & $*$ & 2.5 & $0.0-4.0$ \\
\hline Triglycerides (mmol/L) & 53.4 & 4.4 & $0.6-2.0$ \\
\hline $\mathrm{HbA1c}(\%)$ & 11.2 & 6.1 & $<6.5$ \\
\hline BMI (kg/m²) & 37.0 & 35.5 & $20-25$ \\
\hline Waist circumference (cm) & 113 & 110 & $<90$ \\
\hline Five-year CVD risk $(\%)^{\dagger}$ & $>15$ & 6 & - \\
\hline
\end{tabular}

*HDL and LDL were not able to be assayed on this specimen because of profound lipidaemia ${ }^{\dagger}$ Australian absolute cardiovascular disease risk calculator (http://cvdcheck.org.au) BMI, body mass index; CVD, cardiovascular disease; HbA1c, glycated haemoglobin; HDL, high-density lipoproteins; LDL, low-density lipoproteins

Cases of severe dyslipidaemia require aggressive management to prevent secondary cardiovascular complications. Control of hypercholesterolaemia, hypertriglyceridaemia and diabetes effectively prevents cardiovascular events. ${ }^{4,5}$

\section{ANSWER 5}

Patients with severe dysglycaemia and dyslipidaemia have significant risks of cardiovascular morbidity and mortality unless these modifiable risk factors are aggressively managed. Primary care physicians should note that cardiovascular risk factors are often insidious, and a high index of suspicion needs to be raised in at-risk patient groups.

\section{Author}

Ashraf Saleh MBBS, MNutrSci, BMedSci, FRACGP, FARGP (Emerg Med), People First Health Group, Toowoomba, Qld. shieldaig.reception@ peoplefirsthealthgroup.com.au Conflicts of interest: None.

Funding: None.

Provenance and peer review: Not commissioned, externally peer reviewed.

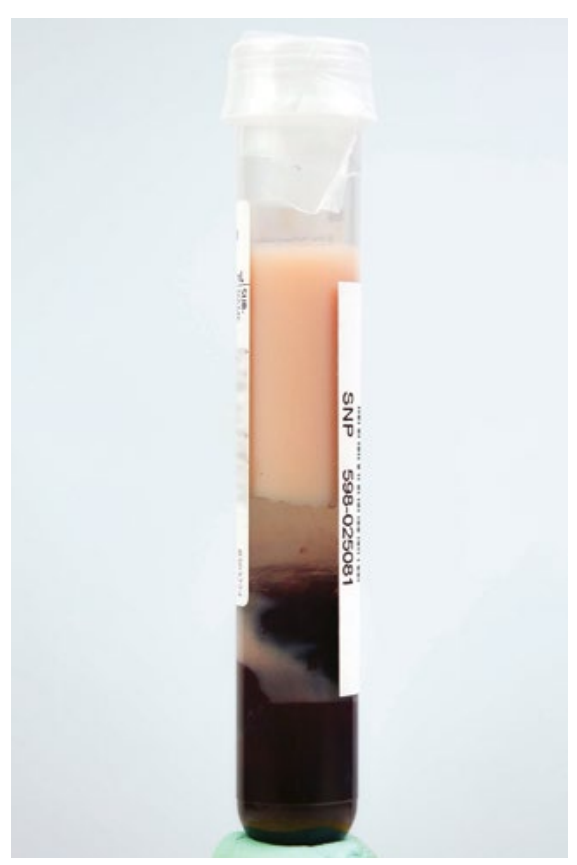

Figure 1. Photograph of the initial fasting blood specimen taken from the patient following centrifugation by the referring laboratory 


\section{Acknowledgements}

The author wishes to thank the People First Health Group for the privilege of accessing patient information from their medical database.

\section{References}

1. Alberti KG, Eckel RH, Grundy SM, et al. Harmonishing the metabolic syndrome: A joint interim statement of the International Diabetes Federation Task Force on Epidemiology and Prevention; National Heart, Lung and Blood Institute; American Heart Association; World Heart Federation; International Atherosclerosis Society; and International Association for the Study of Obesity. Circulation 2009;120(16):164045. doi: 10.1161/CIRCULATIONAHA.109.192644.

2. AlHW Australian GP Statistics and Classification Centre. SAND abstract no. 92 from the BEACH program 2005-06: Prevalence of metabolic syndrome. Sydney: AlHW Australian GP Statistics and Classification Centre, 2006. Available at http://sydney.edu.au/medicine/fmrc/publications/ sand-abstracts/92-Metabolic_syndrome.pdf [Accessed 20 June 2018].

3. Katzmarzyk PT, Church TS, Janssen I, Ross R, Blair SN. Metabolic syndrome, obesity, and mortality: Impact of cardiorespiratory fitness. Diabetes Care 2005;28(2):391-97.

4. Jackson R, Lawes CM, Bennett DA, Milne RJ, Rodgers A. Treatment with drugs to lower blood pressure and blood cholesterol based on an individual's absolute cardiovascular risk. Lancet 2005;365(9457):434-41.

5. Collins R, Armitage J, Parish S, Sleigh P, Peto R: Heart Protection Study Collaborative Group. MRC/BHF Heart Protection Study of cholesterollowering with simvastatin in 5963 people with diabetes: A randomised placebo-controlled trial. Lancet 2003;361(9374):2005-16.

6. Taylor F, Huffman MD, Macedo AF, et al. Statins for the primary prevention of cardiovascular disease. Cochrane Database Syst Rev 2013;(1):CD004816. doi: 10.1002/14651858. CD004816.pub5.

7. Carter AA, Gomes T, Camacho X, Juurlink DN, Shah BR, Mamdani MM. Risk of incident diabetes among patients treated with statins: Population based study. BMJ 2013;346:f2610. doi: 10.1136/ bmj.f2610.

8. Baigent C, Keech A, Kearney PM, et al. Efficacy and safety of cholesterol-lowering treatment: Prospective meta-analysis of data from 90,056 participants in 14 randomised trials of statins. Lancet 2005;366(9493):1267-78. doi: 10.1016/ S0140-6736(05)67394-1.

9. Cholesterol Treatment Trialists' (CTT) Collaborators, Kearney PM, Blackwell L, et al. Efficacy of cholesterol-lowering therapy in 18,686 people with diabetes in 14 randomised trials of statins: A meta-analysis. Lancet 2008;371(9607):117-25. doi: 10.1016/S01406736(08)60104-X.

10. Johnson LA, Arbones-Mainar JM, Fox RG, et al. Apolipoprotein E4 exaggerates diabetic dyslipidemia and atherosclerosis in mice lacking the LDL receptor. Diabetes 2011;60(9):2285-94. doi: 10.2337/db11-0466.

11. National Vascular Disease Prevention Alliance. Absolute cardiovascular disease management: Quick reference guide for health professionals. Melbourne: National Stroke Foundation, 2012.

12. Tonkin A, Barter P, Best J, et al. National Heart Foundation of Australia and the Cardiac Society of Australia and New Zealand: Position statement on lipid management, 2005. Heart Lung Circ 2005;14(4):275-91
13. Yan L, Xu MT, Yuan L, et al. Prevalence of dyslipidemia and its control in type 2 diabetes: A multicenter study in endocrinology clinics of China. J Clin Lipidol 2016;10(1):150-60. doi: 10.1016/j.jacl.2015.10.009.

14. Jacobs MJ, Kleisli T, Pio JR, et al. Prevalence and control of dyslipidemia among persons with diabetes in the United States. Diabetes Res Clin Pract 2005;70(3):263-69. doi: 10.1016/j. diabres.2005.03.032. 